\title{
Effects of the Contents of Various Solvents in One-step Self- etch Adhesives on Shear Bond Strengths to Enamel and Dentin
}

\author{
FA Ageel ${ }^{1}, \mathrm{MQ}$ Alqahtani ${ }^{2}$
}

\begin{abstract}
Aim: The aim of this study was to evaluate the shear bond strengths (SBSs) of one-step self-etch adhesives containing different co-solvents to enamel and dentin and to determine the failure modes of tested specimens.

Materials and methods: Two hundred and forty $(n=240)$ sound human molars were used. The buccal surfaces of each tooth were ground and polished to obtain flat enamel surfaces $(n=120)$ or to expose the underlying dentin $(n=120)$. The specimens with exposed enamel or dentin were randomly divided into four main groups $(n=30)$ according to the one-step self-etch adhesives used: Bond-1 SF, OptiBond All-InOne, G-aenial, and Single Bond Universal adhesive. All the main groups were then subdivided into two subgroups (control and thermocycling subgroups) ( $n=15$ ). After bonding procedures, a composite restoration (Filtek Z250) was applied in a vinyl tube and condensed against the cured adhesive bonding agent, to form a resin cylinder. The specimens were stored in distilled water at $37^{\circ} \mathrm{C}$ for 24 hours (control and thermocycling subgroups), followed by thermocycling $\left(5-55^{\circ} \mathrm{C} / 5,000\right.$ cycles + storage in artificial saliva for 2 weeks) (thermocycling subgroup). They were subjected to SBS testing in a universal testing machine at a crosshead speed of $0.5 \mathrm{~mm} /$ minute. After being shear-tested, all fractured samples were examined by means of a Hirox Digital Microscope at 50x magnification for failure analysis. The data were analyzed by one-way analysis of variance followed by Tukey's post hoc analysis at a $p$ value of $\leq 0.05$.

Results: OptiBond All-In-One adhesive showed significantly higher mean SBS values on both types of tooth structures (enamel and dentin) and under different conditions (control and thermocycled) compared with the other three adhesives $(p<0.001$ ), except in the enamel-thermocycled group, where the Single Bond Universal adhesive showed higher mean SBS but without a significant difference compared with the OptiBond All-In-One adhesive $(p=0.266)$, and there was no significant difference between OptiBond All-In-One and G-aenial Bond in the same group $(p=0.192)$. Conversely, Bond-1 SF showed significantly lower mean SBS values compared with those of the other three adhesives on different types of tooth structures and under different conditions (control and thermocycled) $(p<0.001)$.

Conclusion: One-step self-etch adhesives containing ethanol as a solvent or co-solvent showed higher SBS compared with the other self-etching bonding agents. The bond strength values of these adhesives to dentin are significantly higher than those to enamel.

Clinical relevance: The types of solvents of one-step self-etch adhesives had an effect on SBS, and the absence of solvent in those adhesives would adversely influence their performance.

Keywords: Dentin, Enamel, Laboratory research, Self-etch adhesives, Shear bond strength, Solvents.

The Journal of Contemporary Dental Practice (2019): 10.5005/jp-journals-10024-2683
\end{abstract}

\section{INTRODUCTION}

Tooth-colored restorations are being used more than ever before due to patients' demands for esthetics and due to the advancements in dental adhesive technology. Bonded restorations have more advantages than nonbonded restorations, including conservation of tooth structure, reduction of microleakage at the restorationtooth interface, postoperative sensitivity, and marginal staining. ${ }^{1}$

Bonding to tooth structure can be achieved through different adhesive systems, including etch-and-rinse adhesives, self-etch systems, and glass ionomer. The main challenge of dental adhesives is to bind effectively to tooth structure that includes both enamel and dentin. Bonding to enamel has been reliable and durable since Buonocore introduced the acid-etch technique in 1955. Conversely, bonding to dentin is more challenging, due to its high organic composition and wet tubular structure. ${ }^{2}$

Most conventional adhesive systems (etch-and-rinse) can produce a strong resin-dentin bond by infiltrating dentinal surfaces after acid-etching and creating a hybrid or resin-reinforced dentin layer, which is important for micromechanical retention. ${ }^{3}$ This system, however, has demonstrated some drawbacks that influence their bonding performance. Postoperative sensitivity may occur,
${ }^{1}$ Department of Restorative Dentistry, Prince Sultan Military Medical City, Riyadh, Kingdom of Saudi Arabia

${ }^{2}$ Department of Restorative Dental Sciences, College of Dentistry, King Saud University, Riyadh, Kingdom of Saudi Arabia

Corresponding Author: FA Ageel, Department of Restorative Dentistry, Prince Sultan Military Medical City, Riyadh, Kingdom of Saudi Arabia, Phone: +966 114777714, e-mail: fbinaqeel@psmmc.med.sa

How to cite this article: Ageel FA, Alqahtani MQ. Effects of the Contents of Various Solvents in One-step Self-etch Adhesives on Shear Bond Strengths to Enamel and Dentin. J Contemp Dent Pract 2019;20(11):1260-1268.

Source of support: Nil

Conflict of interest: None

with incomplete infiltration of resin in the demineralized dentin. ${ }^{4}$ Also, overdrying may cause collagen collapse after etching. ${ }^{5}$ Furthermore, resin-bonding is technique-sensitive, which requires meticulous moisture control. ${ }^{6}$

Dental adhesives have undergone a continuous development to reduce the technique sensitivity and minimize the number 
of application steps. ${ }^{7}$ As a result, self-etch adhesive bonding agents were introduced, since they contain acidic monomers that condition and prime the dental substrate at the same time. They are also comprised of different components for bonding in a single solution, such as solvents (acetone, ethanol, or water), resin components, photo-initiators, and inhibitors. ${ }^{8}$ The self-etch approach can be classified, according to the number of steps required for application, as one-step or two-step self-etch. ${ }^{8}$ Further, based on acid aggressiveness, they can be subdivided into strong, intermediate, mild, and ultra-mild self-etch adhesives. ${ }^{9}$

Self-etch adhesives have some advantages compared with conventional adhesives, such as less postoperative sensitivity and less technique sensitivity. ${ }^{10}$ However, it is not clear whether these materials have high and durable bond strength. ${ }^{11}$ Also, even if the demineralized area of adhesion is penetrated by resin, the long-term stability of the hybrid layer is unknown. Furthermore, incomplete polymerization of this interdiffusion area might occur due to diffusion gradients created by dentinal tissues, moisture contents, residual solvents, or phase separation of monomers. ${ }^{6,12}$

The chemical composition of self-etch adhesives that include co-solvents plays an essential role in bonding performance. ${ }^{13}$ In self-etch adhesives, hydrophilic resin monomers are often dissolved in evaporative solvents, such as acetone, ethanol, water, and combinations thereof. Solvents are responsible for water displacement from collagen networks and infiltration of resin monomer into interfibrillar dentin. ${ }^{14}$

Several published studies have measured the effectiveness of self-etch adhesives in bonding to enamel and dentin. Meanwhile, studies have reported controversial results regarding their performance and bond strength. ${ }^{15-19}$ Some studies compared bond strengths of self-etch adhesives based on their $\mathrm{pH}^{15,17}$ and a few studies found in the literature compared bond strengths of different self-etch adhesives according to the ingredients of their co-solvents. ${ }^{20,21}$ However, the results from those limited studies are difficult to compare due to different experimental designs, protocols, and aging processes. The aim of this study, therefore, was to evaluate the SBSs of one-step self-etch adhesives containing different co-solvents to enamel and dentin and to determine the failure modes of tested specimens. There were two null hypotheses: first, that there would be no significant difference in SBSs to enamel and dentin with different one-step self-etch adhesives; and second, that there would be no significant effect on SBSs with different co-solvent contents of one-step self-etch adhesives.

\section{Materials and Methods}

\section{Materials Tested}

The materials used in this study included three one-step self-etch adhesives with different solvent content and one solvent-free adhesive: Bond1 SF (Pentron Clinical Corporation, Wallingford, $C T$, USA); OptiBond All-In-One (Kerr Corporation, Orange, CA, USA); G-aenial Bond (GC Corporation, Tokyo, Japan); and Single Bond Universal adhesive (3M Deutschland, Neuss, Germany). All the materials used in the study are shown in Table 1.

\section{Tooth Selection}

In this study, 240 ( $n=240)$ sound human molars were used within one month of extraction (Flowchart 1). Each tooth was cleaned then polished by using ultrasonic scaler followed by application of nonfluoridated pumicein a rubbercupmountedinaslow-speed handpiece (KaVo EWL, No. 6412500; KaVo Dental GmbH, Biberach, Germany).
After being cleaned and polished, all teeth were stored in distilled water with a $0.05 \%$ thymol solution in a dark container at room temperature $\left(20-25^{\circ} \mathrm{C}\right)$ until being mounted. The selected teeth for this study were free of any defects such as caries, cracks, abrasion facets, fluorosis, and damage from extraction. All teeth were examined by stereomicroscopy (Swift Instruments Inc., San Jose, (A, USA) to eliminate teeth with cracks or hypoplastic defects.

\section{Preparation of Specimens}

Each crown was separated from the roots $2 \mathrm{~mm}$ apical to the cement-enamel junction by means of a water-cooled slow-speed diamond saw (Isomet 2000; Buehler, Lake Bluff, IL, USA). Self-cure acrylic resin was loaded into polyvinyl chloride cylindrical molds (diameter, $24 \mathrm{~mm}$; height, $16 \mathrm{~mm}$ ), which were used for mounting the teeth. Each tooth was embedded in the acrylic resin in such a way that its buccal surface faced up for bonding procedures.

After being mounted, the specimens were divided randomly into two main groups (enamel and dentin), each with 120 specimens. For the enamel group, the buccal surface of each specimen was flattened, and for the dentin group, the buccal surface was ground (diameter of approximately $5 \mathrm{~mm}$ ). The specimens were then polished with wet silicon carbide papers, with the same sequence used for both groups (180-, 240-, 400-, and 600-grit) (Automata; Jean-Wirtz GmbH \& Co., Charlottenstrasse, Düsseldorf, Germany). Before bonding procedures, all specimens were examined under a stereomicroscope (Swift Instruments, Inc.) for verification that tooth structure had been exposed.

The specimens with enamel or dentin exposed were randomly divided into four main groups $(n=30)$ according to the one-step self-etch adhesives used. Each material group was then subdivided into two subgroups ( $n=15)$, control and thermocycling. In the first group (control), bonding procedures and resin composite application were carried out, followed by storage in distilled water at $37^{\circ} \mathrm{C}$ for 24 hours (without thermocycling procedures). For the second group, bonding procedures and resin composite application were carried out, followed by storage in distilled water at $37^{\circ} \mathrm{C}$ for 24 hours, after which thermocycling procedures were carried out, followed by storage for two weeks in artificial saliva at $37^{\circ} \mathrm{C}$.

\section{Bonding Procedure}

All bonding procedures were performed according to the manufacturers' instructions for the tested materials (Table 1). The regions of interest for adhesion were limited in each sample by means of a customized metal ring (diameter, $5 \mathrm{~mm}$ ). Light-curing procedures were carried out with a high-power light-emittingdiode curing light (BluePhase G2; Ivoclar-Vivadent, Schaan, Liechtenstein) delivering an irradiance exposure with an average of $1,200 \mathrm{~mW} / \mathrm{cm}^{2} \pm 10 \%$ and verified with a curing radiometer (Ivoclar-Vivadent).

\section{Resin Composite Application}

After the bonding procedure, each specimen was placed in the compression bonding apparatus for the application of the resin composite (Filtek Z250, shade A2; 3M ESPE Dental Products, St. Paul, MN, USA) in the vinyl tube (height, $2 \mathrm{~mm}$; diameter, $4 \mathrm{~mm}$ ) and condensed against the cured adhesive bonding agent, to form a resin cylinder. A glass slide was placed over a Mylar strip to standardize the distance between the guide of the light-curing unit and the resin composite, and the sample was then light-cured for 40 seconds. 
Table 1: Materials used in the study

\begin{tabular}{|c|c|c|c|c|}
\hline Material & Manufacturer & Material composition & Solvent & Application procedure \\
\hline $\begin{array}{l}\text { Filtek }^{\mathrm{TM}} \text { Z250 } \\
\text { microhybrid } \\
\text { resin composite (LOT } \\
\text { N749365) }\end{array}$ & $\begin{array}{l}\text { 3M ESPE Dental Products, } \\
\text { St. Paul, MN, USA }\end{array}$ & $\begin{array}{l}\text { Bis-GMA, BisEMA, UDMA, zirconia/ } \\
\text { silica ( } 78 \% \text { w/w), barium glass, } \\
\text { ytterbium trifluoride, and mixed } \\
\text { oxide prepolymer }\end{array}$ & - & $\begin{array}{l}\text { - Place Filtek Z250-shade A2 } \\
\text { - Light-cure each increment for } \\
40 \text { seconds }\end{array}$ \\
\hline $\begin{array}{l}\text { Bond- } 1^{\text {TM }} \text { SF (LOT } \\
5981609)(\mathrm{pH}=3-4)\end{array}$ & $\begin{array}{l}\text { Pentron Clinical } \\
\text { Corporation, Wallingford, } \\
\text { CT, USA }\end{array}$ & $\begin{array}{l}\text { UDMA, TEGDMA, HEMA, and } \\
\text { 4-META resins; silane-treated } \\
\text { barium-borosilicate glasses; silica } \\
\text { with initiator, stabilizers, and UV } \\
\text { absorber; organic and/or inorganic } \\
\text { pigments, and opacities }\end{array}$ & None & $\begin{array}{l}\text { - Dip applicator and spread evenly } \\
\text { - } \text { Rub for } 20 \text { seconds } \\
\text { - } \quad \text { Light-cure for } 10 \text { seconds }\end{array}$ \\
\hline \multirow[t]{3}{*}{$\begin{array}{l}\text { OptiBond }{ }^{\circledR} \text { All-In- } \\
\text { One (LOT 5856589) } \\
(\mathrm{pH}=2.5)\end{array}$} & \multirow[t]{3}{*}{$\begin{array}{l}\text { Kerr Corporation, Orange, } \\
\text { CA, USA }\end{array}$} & \multirow{3}{*}{$\begin{array}{l}\text { GPDM, mono- and difunctional } \\
\text { methacrylate monomers, HEMA } \\
\text { camphorquinone-based photo- } \\
\text { initiator, fluoride-releasing } \\
\text { fillers-sodium hexafluorosilicate } \\
\text { and ytterbium fluoride }\end{array}$} & Water & $\begin{array}{l}\text { Scrub two consecutive coats of } \\
\text { adhesive with disposable applicator } \\
\text { for } 20 \text { seconds each }\end{array}$ \\
\hline & & & Ethanol & $\begin{array}{l}\text { - Air-thin adhesive for } 5 \text { seconds with } \\
\text { medium-force stream of air }\end{array}$ \\
\hline & & & Acetone & $\begin{array}{l}\text { Light-activate adhesive for } \\
10 \text { seconds }\end{array}$ \\
\hline $\begin{array}{l}\text { G-aenial }{ }^{T M} \text { Bond (LOT } \\
\text { 1608051) }(\mathrm{pH}=1.5)\end{array}$ & $\begin{array}{l}\text { GC Corporation, Tokyo, } \\
\text { Japan }\end{array}$ & $\begin{array}{l}\text { Dimethacrylate, 4-MET, phosphoric } \\
\text { acid ester monomer, silicon dioxide, } \\
\text { distilled water, and photo-initiator }\end{array}$ & Acetone & $\begin{array}{l}\text { - Apply and leave for } 10 \text { seconds } \\
\text { - Dry with an air jet for } 5 \text { seconds } \\
\text { - Light-cure for } 10 \text { seconds }\end{array}$ \\
\hline $\begin{array}{l}\text { Single Bond Universal } \\
\text { (LOT N749365) } \\
(\mathrm{pH}=2.7)\end{array}$ & $\begin{array}{l}\text { 3M Deutschland, Neuss, } \\
\text { Germany }\end{array}$ & $\begin{array}{l}\text { MDP phosphate monomer, } \\
\text { dimethacrylate resins, HEMA, } \\
\text { methacrylate-modified polyalkenoic } \\
\text { acid copolymer, filler, water, } \\
\text { initiators, silane }\end{array}$ & Ethanol & $\begin{array}{l}\text { - Apply the adhesive and rub it for } 20 \\
\text { seconds } \\
\text { - Direct a gentle stream of air for } \\
\text { about } 5 \text { seconds } \\
\text { - Light-cure for } 10 \text { seconds }\end{array}$ \\
\hline
\end{tabular}

Bis-GMA, bisphenol A diglycidyl methacrylate; bis-EMA, ethoxylated bisphenol A glycol dimethacrylate; UDMA, urethane dimethacrylate; TEGDMA, triethylene glycol dimethacrylate; HEMA, 2-hydroxyethyl methacrylate; 4-MET, 4-methacryloyloxyethyl trimellitic acid; GPDM, glycerol phosphate dimethacrylate; 10-MDP, and 10-methacryloyloxydecyl dihydrogenphosphate

Flowchart 1: Specimen distribution

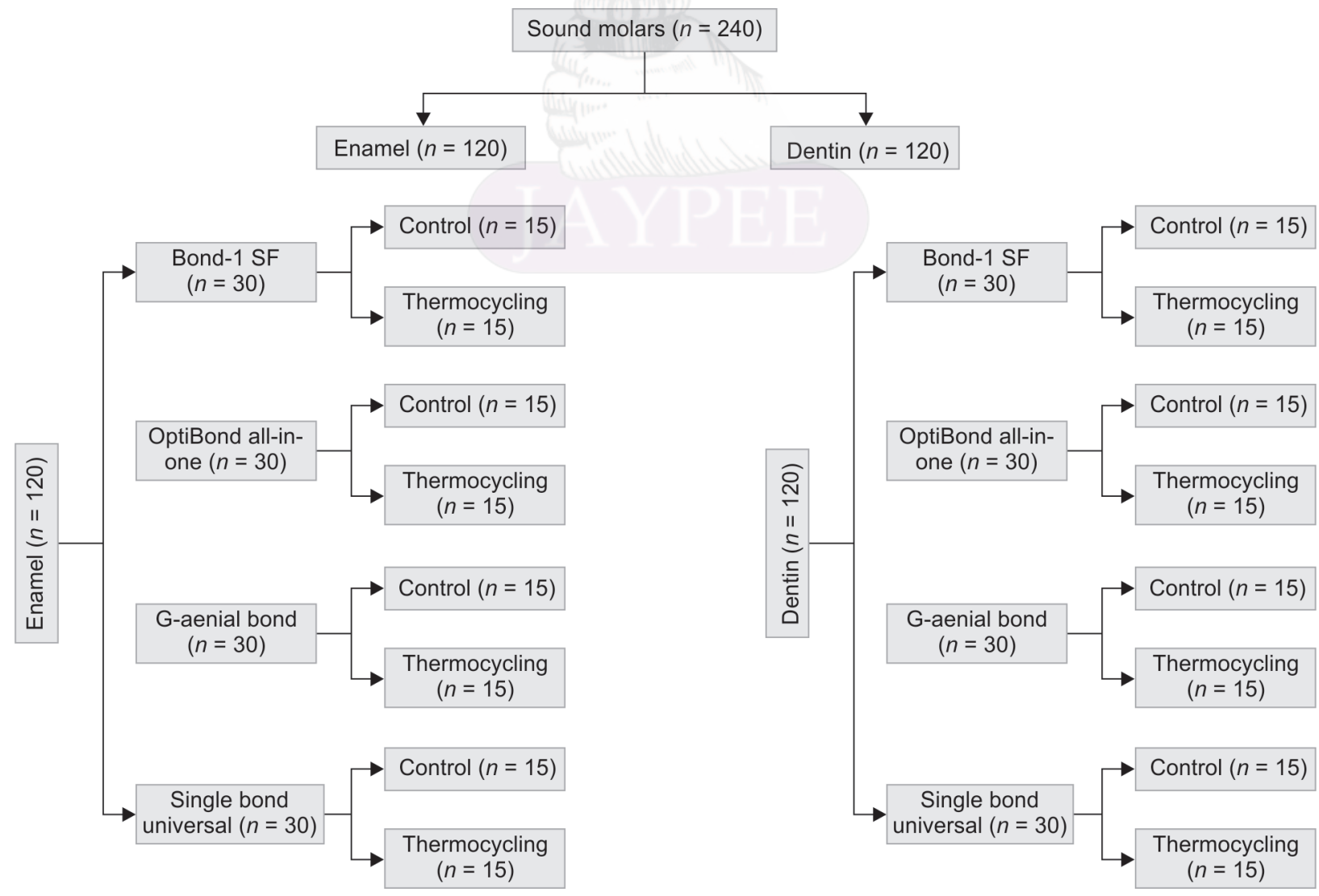




\section{Thermocycling Groups}

After the bonding procedures, the samples were stored in distilled water at $37^{\circ} \mathrm{C}$ for 24 hours and subjected to 5,000 cycles in a thermocycling apparatus (Thermocycler 1100; SD Mechatronik, Aspach, Germany) between $5^{\circ} \mathrm{C}$ and $55^{\circ} \mathrm{C}$ with a dwell time of 30 seconds. $^{22}$

\section{Artificial Saliva Storage}

After being thermocycled, the specimens in the second subgroup were immersed in $70 \mathrm{~mL}$ of artificial saliva at $37^{\circ} \mathrm{C}$ for two weeks. The solution of artificial saliva used in this study was composed of $1.0 \mathrm{~g}$ sodium carboxymethylcellulose, $4.3 \mathrm{~g}$ xylitol, $0.1 \mathrm{~g}$ potassium chloride, $0.1 \mathrm{~g}$ sodium chloride, $0.02 \mathrm{mg}$ sodium fluoride, $5.0 \mathrm{mg}$ magnesium chloride, $5.0 \mathrm{mg}$ calcium chloride, $40 \mathrm{mg}$ potassium phosphate, and $1 \mathrm{mg}$ potassium thiocyanate diluted in $100 \mathrm{~g}$ distilled deionized water at $\mathrm{pH} 7 .^{23}$ The artificial saliva was changed every day during the two-week storage.

\section{SBS Testing}

The specimens were subjected to SBS testing in a universal testing machine (Instron 5965; ITW Instron, Norwood, MA, USA) with a load cell of $5 \mathrm{kN}$ (Fig. 1). Each sample was mounted in a customized metal holder while a knife-edged rod with a width of $0.5 \mathrm{~mm}$ was applied at the adhesive-tooth interface at a cross-head speed of $0.5 \mathrm{~mm} /$ minute (Fig. 2). Fracture load was recorded in megapascals (MPa), obtained by dividing the load at failure by the bonded crosssectional area.

\section{Failure Analysis}

After shear testing was performed, all fractured samples were examined for failure by means of a Hirox Digital Microscope $(\mathrm{KH}-$ 7700; Hirox Co. Ltd, Tokyo, Japan) at 50× magnification. Failure modes were classified as "adhesive failure," failure between the bonding agent and the tooth $(A)$; "cohesive failure," failure within the resin composite material $\left(C_{C}\right)$ or the tooth structure $\left(C_{T}\right)$; or "mixed failure" (M).

\section{Statistical Analysis}

Data were analyzed with SPSS pc+ version 21.0 statistical software (SPSS Inc., Chicago, IL, USA). Descriptive statistics (mean, standard deviation (SD), and percentages) were used to describe the quantitative and categorical outcome variables. One-way analysis

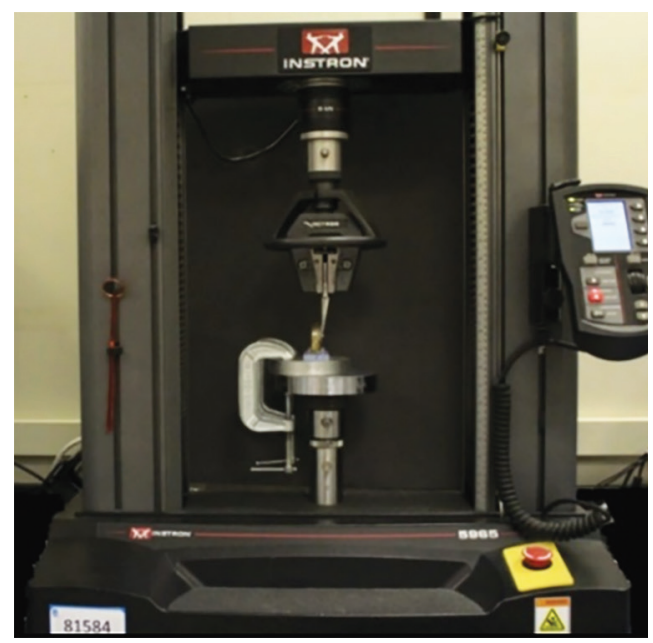

Fig. 1: Universal testing machine (Instron) of variance and Tukey's post hoc analysis were used to compare the mean values of SBS across the categorical study variables. At $\alpha=0.05$ and power $=0.95$, the sample size for each group was estimated to be at least 15 of the total sample size 240 . A $p$ value of $\leq 0.05$ was used to report the statistical significance of results.

\section{Results}

The mean SBSs and the SD for all groups of different adhesives with statistical analysis are presented and summarized in Table 2 and Figure 3. The types of tooth structures (enamel and dentin) and different conditions (control and thermocycled) had significant effects on the SBS of all the adhesives $(p<0.001)$.

\section{Bond-1 SF Adhesive Agent}

The mean SBS values are listed here from highest to lowest: dentin-control $(11.54 \pm 2.05 \mathrm{MPa})$, dentin-thermocycled $(8.76 \pm 0.93 \mathrm{MPa})$, enamel-control $(8.12 \pm 0.49 \mathrm{MPa})$, and enamelthermocycled ( $3.47 \pm 1.03 \mathrm{MPa}$ ) (Table 2 and Fig. 3 ). Mean SBS values of this adhesive to dentin under different conditions were significantly higher compared with the mean SBS values to enamel under the same different conditions $(p<0.001)$. The thermocycling procedure significantly reduced the mean SBS values compared with the control procedure on each type of tooth structure (enamel or dentin) $(p<0.001)$.

\section{OptiBond All-In-One Adhesive Agent}

The mean SBS values are listed here from highest to lowest: dentin-control $(25.92 \pm 1.55 \mathrm{MPa})$, dentin-thermocycled $(25.46 \pm 5.78 \mathrm{MPa})$, enamel-control $(17.67 \pm 2.44 \mathrm{MPa})$, and enamel一thermocycled ( $15.18 \pm 2.30 \mathrm{MPa}$ ) (Table 2 and Fig. 3). Mean SBS values of this adhesive to dentin under different conditions were significantly higher compared with the mean SBS values to enamel under the same different conditions ( $p<0.001)$. The thermocycling procedure reduced the mean SBS values compared with the control procedure on each type of tooth structure (enamel or dentin) but without a significant difference ( $p=0.205$ and $p=0.983$, respectively).

\section{G-aenial Bond Adhesive Agent}

The mean SBS values are listed here from highest to lowest: dentin-control $(15.03 \pm 3.16 \mathrm{MPa})$, enamel-thermocycled $(13.95 \pm 1.17 \mathrm{MPa})$, dentin-thermocycled $(13.45 \pm 1.40 \mathrm{MPa})$, and

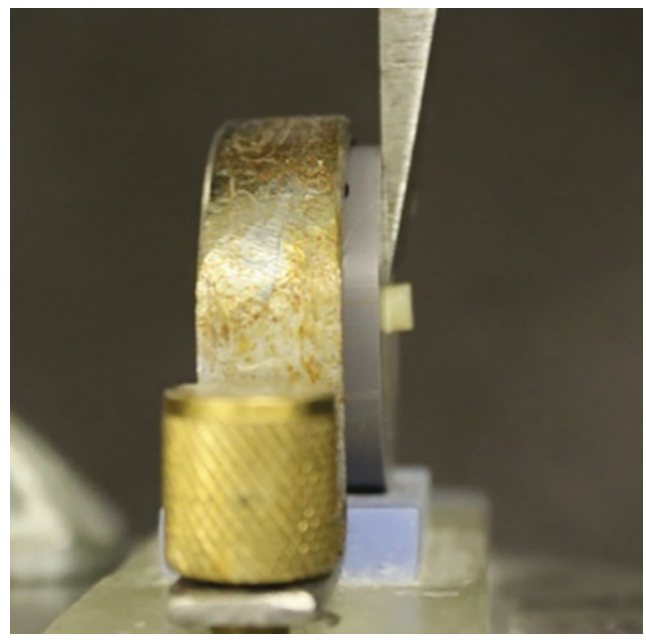

Fig. 2: Knife-edged rod with a width of $0.5 \mathrm{~mm}$ 
Effects of the Contents of Various Solvents in Self-etch

Table 2: Mean shear bond strengths (SD) of all the materials in both surfaces (enamel and dentin) under different conditions (control and thermocycled)

\begin{tabular}{|c|c|c|c|c|}
\hline \multirow[b]{3}{*}{ Materials } & \multicolumn{2}{|c|}{ Enamel } & \multicolumn{2}{|c|}{ Dentin } \\
\hline & Control & Thermocycled & Control & Thermocycled \\
\hline & $\begin{array}{l}\text { SBS in MPa mean } \\
\text { value (SD) }\end{array}$ & $\begin{array}{l}\text { SBS in MPa mean } \\
\text { value (SD) }\end{array}$ & $\begin{array}{l}\text { SBS in MPa mean } \\
\text { value (SD) }\end{array}$ & $\begin{array}{l}\text { SBS in MPa mean } \\
\text { value (SD) }\end{array}$ \\
\hline Bond-1 SF & $8.12(0.49)^{\mathrm{a}, \mathrm{A}}$ & $3.47(1.03)^{\mathrm{a}, \mathrm{B}}$ & $11.54(2.05)^{a_{1} \mathrm{C}}$ & $8.76(0.93)^{a, A}$ \\
\hline OptiBond All-In-One & $17.67(2.44)^{b, A}$ & $15.18(2.30)^{b, c, d, d, A}$ & $25.92(1.55)^{\mathrm{b}, \mathrm{B}}$ & $25.46(5.78)^{b, B}$ \\
\hline G-aenial Bond & $11.89(1.24)^{c, A}$ & $13.95(1.17)^{c, B, C}$ & $15.03(3.16)^{c, B, C}$ & $13.45(1.40)^{\mathrm{c}, \mathrm{C}, \mathrm{A}}$ \\
\hline $\begin{array}{l}\text { Single Bond Universal } \\
\text { adhesive }\end{array}$ & $17.46(2.24)^{\mathrm{b}, \mathrm{A}}$ & $16.30(1.84)^{d, A}$ & $23.11(2.21)^{d, B}$ & $21.54(2.60)^{\mathrm{d}, \mathrm{B}}$ \\
\hline
\end{tabular}

$N=15$ for each group with 240 total specimens

According to Tukey's post hoc test: The same superscript small letters indicate no statistically significant difference (columns) $(p \leq 0.05)$; and the same superscript capital letters indicate no statistically significant difference (rows) $(p \leq 0.05)$

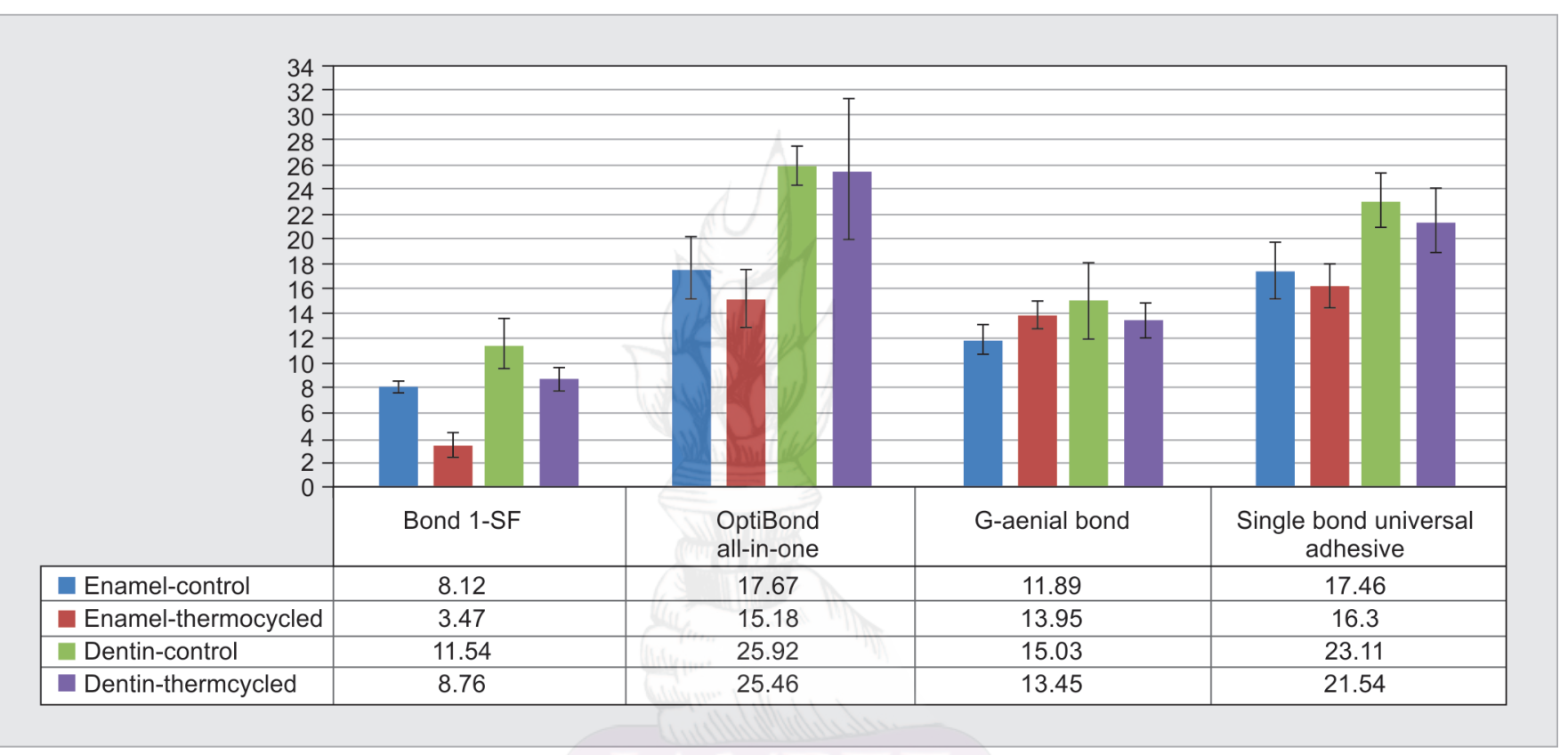

Fig. 3: Mean SBSs with SD of tested one-step self-etch adhesives in MPa on enamel and dentin structures under different conditions (control and thermocycled)

enamel-control (11.89 $\pm 1.24 \mathrm{MPa})$ (Table 2 and Fig. 3). Mean SBS values of this adhesive to dentin under control conditions were significantly higher compared with the mean SBS values to enamel under the same conditions ( $p<0.001)$, while the mean SBS values of this adhesive to enamel under thermocycled conditions were higher compared with the mean SBS values to dentin under the same conditions, but without a significant difference ( $p=0.893)$. The thermocycling procedure significantly increased the mean SBS values compared with the control procedure on enamel $(p=0.025)$, while the opposite effect occurred on dentin structures, but without a significant difference $(p=0.124)$.

\section{Single Bond Universal Adhesive Agent}

The mean SBS values are listed here from highest to lowest: dentin-control $(23.11 \pm 2.21 \mathrm{MPa})$, dentin-thermocycled $(21.54 \pm 2.60 \mathrm{MPa})$, enamel-control $(17.46 \pm 2.24 \mathrm{MPa})$, and enamel-thermocycled ( $16.3 \pm 1.84 \mathrm{MPa}$ ) (Table 2 and Fig. 3). Mean SBS values of this adhesive to dentin under different conditions were significantly higher compared with the mean SBS values to enamel under the same different conditions $(p<0.001)$. The thermocycling procedure reduced the mean SBS values compared with the control procedure on each type of tooth structure (enamel or dentin) but without a significant difference ( $p=0.493$ and $p=0.231$, respectively).

OptiBond All-In-One adhesive showed significantly higher mean SBS values on both types of tooth structures (enamel and dentin) and under different conditions (control and thermocycled) compared with the other three adhesives $(p<0.001)$, except that in the enamel-thermocycled group, the Single Bond Universal adhesive showed higher mean SBS but without a significant difference compared with the OptiBond All-In-One adhesive $(p=0.266)$, and there was no significant difference between OptiBond All-In-One and G-aenial Bond in the same group ( $p=0.192)$. Conversely, Bond-1 SF showed significantly lower mean SBS values compared with the other three adhesives on different types of tooth structures and under different conditions (control and thermocycled) $(p<0.001)$ (Table 2 and Fig. 3). 


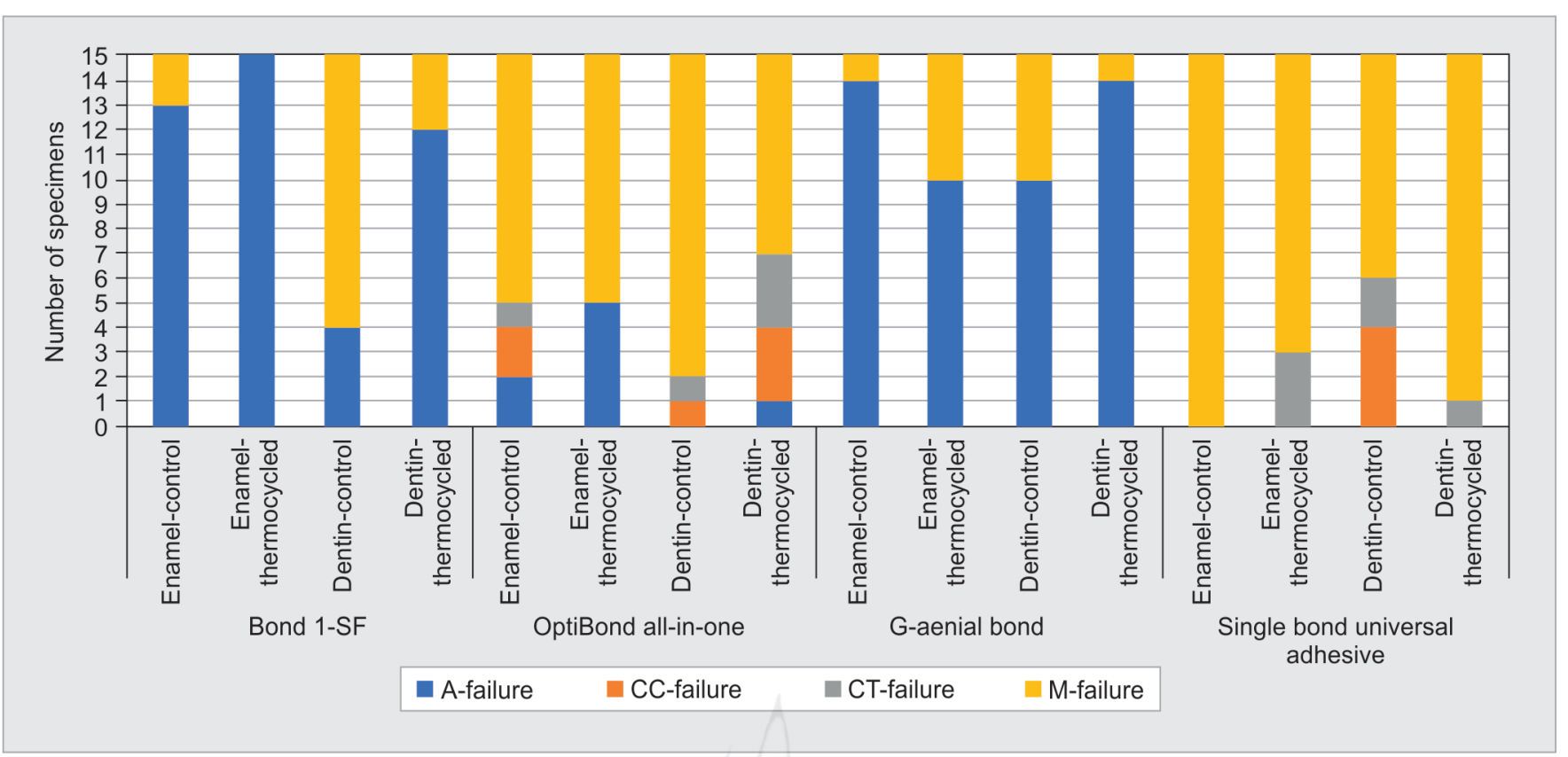

Fig. 4: Failure mode distribution

\section{Failure Modes}

The failure modes for different adhesives (Bond-1 SF, OptiBond All-In-One, G-aenial Bond, and Single Bond Universal adhesives) on different types of tooth structures (enamel and dentin) and under different conditions (control and thermocycled) are illustrated in Figure 4. Most adhesive failures were observed when Bond-1 SF and G-aenial Bond adhesives were used, while mixed failures were observed when OptiBond All-in-One and Single Bond Universal adhesives were used.

\section{Discussion}

The present research aimed to evaluate the SBSs to enamel and dentin of one-step self-etch adhesives with different solvents. According to the study's results, the first null hypothesis can be rejected, since there was a statistically significant difference in SBSs to enamel and dentin when different one-step self-etch adhesives were used. The second null hypothesis, claiming that the SBSs of one-step self-etch adhesives with different solvents would not be significant, also had to be rejected, since there was a significant difference between different adhesives with different solvent contents.

In this study, the SBS test was used due to its simplicity compared with the tensile bond strength test, which is more complicated, with a high risk of premature failure of the specimen during preparation. One-step self-etch dental adhesives are a complex mixture of components of reactive monomers, an association of dissolved hydrophilic and hydrophobic monomers, cross-linkers, initiators, and solvents (such as water, acetone, and ethanol). ${ }^{24}$ The presence of solvent is necessary, but there is concern regarding incomplete solvent evaporation and its detrimental effect on monomer infiltration and polymerization. ${ }^{25}$ For that reason, numerous techniques have been proposed to decrease water sorption and degradation of collagen, hence improving monomer infiltration. One such technique is the use of a solvent-free adhesive, so called because it does not contain water, ethanol, or acetone as a conventional solvent.
In the present study, one-step self-etch adhesives containing different solvents demonstrated significantly higher bond strengths compared with solvent-free one-step self-etch adhesives, even after the application of the thermocycling procedure and two-week storage in artificial saliva. Some studies have measured SBSs of one-step self-etch adhesives with and without solvents, and their results are in accordance with those of the present study. ${ }^{21,26,27}$

Bond-1 SF was used as a solvent-free self-etch adhesive; it demonstrated the lowest SBS values to enamel and dentin in both procedures (control and thermocycling). Although Bond-1 SF is categorized as a solvent-free self-etch adhesive, it should be noted that it contains 2-hydroxyethyl methacrylate (HEMA), a lowmolecular-weight monomer that acts as a solvent. ${ }^{28} 2$-Hydroxyethyl methacrylate is the most common monomer present in adhesive, due to its positive effect on the adhesive mechanism by the prevention of phase separation. ${ }^{29}$ The presence of HEMA (10\%) in small amounts improves the bond strength and wettability of a one-step self-etch adhesive. However, it has some disadvantages when added in higher concentrations: The bond strength and the polymerization are compromised due to increased osmosis and water uptake. ${ }^{30}$ Also, Bond-1 SF contains 4-MET monomer, which can form ionic bonds with calcium in hydroxyapatite. Yoshida and others showed that the resulting Ca-4MET salt has relatively high solubility and is therefore not very stable. ${ }^{31}$

Additionally, the $\mathrm{pH}$ value of Bond- $1 \mathrm{SF}(\mathrm{pH}=3-4)^{21}$ is comparatively higher than those of OptiBond All-In-One $(\mathrm{pH}=$ $2.5),{ }^{10} \mathrm{G}$-aenial $(\mathrm{pH}=1.5),{ }^{15}$ and Single Bond Universal $(\mathrm{pH}=2.7),{ }^{32}$ which might decrease dentin demineralization depth. This factor, among the other compositional factors of the material, might affect infiltration capacity and lower bond strength. However, further studies are needed to support those hypotheses.

The present investigation revealed that the bond strengths of OptiBond All-In-One were the highest among the materials tested. The presence of three solvents-water, ethanol, and acetonecould balance evaporation and optimize infiltration. The presence of water in self-etch adhesives is important for ionization of the acidic monomers but has the disadvantage of low vapor pressure. While 
acetone has the highest vapor pressure, which ensures maximum removal of solvent, ethanol ensures wetness of the substrate and prevents dehydration. ${ }^{28}$

Another explanation for the good performance of OptiBond AllIn-One could be the content of glycerol phosphate dimethacrylate monomer (GPDM) in its formulation. This is the only material among the tested adhesives that contains GPDM, which enhances hydrophobic monomer infiltration, reducing phase separation. ${ }^{33}$

$\mathrm{G}$-aenial Bond one-step self-etch adhesive was used as an acetone-containing adhesive and showed lower SBS results compared with ethanol-containing adhesives. The present result is in agreement with those of the study conducted by Chaudhary and colleagues, who concluded that the adhesives containing ethanol-based solvents showed better bonding than did acetoneand water-based self-etch adhesives. ${ }^{20}$ Acetone as a solvent forms low hydrogen bonds that cannot expand shrunken demineralized collagen. Also, it has high vapor pressure compared with ethanol, which allows the solvent to evaporate easily. However, after the solvent evaporates, the viscosity of the adhesive increases, which decreases the ability of the adhesive to penetrate the exposed collagen fibers, producing incomplete hybrid layers. ${ }^{34}$

Furthermore, acetone has a low boiling temperature compared with that of ethanol and thus requires careful observation and handling of the product, since acetone might be lost during storage. ${ }^{35}$ Although G-aenial Bond contains 4-MET monomer, which can chemically interact with hydroxyapatite crystals, this adhesive is HEMA-free, meaning that it lacks the component that increases hydrophilicity and promotes adhesion by enhancing the wetting of dentin.

Single Bond Universal adhesive is an ethanol-and water-based one-step self-etch adhesive. It produced a high SBS result, which was not statistically significantly different from that of OptiBond All-In-One. It is postulated that the adhesive containing ethanol has a low-viscosity solution, which allows for better penetration and wetting of the substrate. Also, ethanol has the effect of water displacement, so the role of water in the infiltration of hydrophobic monomer into wet dentin is expected to be reduced. ${ }^{36}$

Single Bond Universal has 10-methacryloyloxydecyl dihydrogen phosphate (MDP) monomer in its composition, which bonds chemically to hydroxyapatite. Yoshida and colleagues showed that an effective chemical interaction occurs between MDP and hydroxyapatite, forming a stable MDP-Ca salt which makes the adhesive interface more resistant to biodegradation. ${ }^{37}$ The solvent and functional monomer type may explain the high SBS with this adhesive. It was expected that Single Bond Universal and OptiBond All-In-One would have similar results, since they are ethanol- and water-based adhesives and have functional monomers, but Single Bond Universal showed lower results than the latter. This could be attributed to the presence of polyalkenoic acid copolymer (Vitrebond Copolymer), in combination with MDP. The polyalkenoic acid copolymer has a high molecular weight that could impair the MDP monomer in bonding with hydroxyapatite and prevent monomer approximation during polymerization. ${ }^{38}$

In the present laboratory study, thermocycling procedures and two-week storage in artificial saliva were used to simulate oral conditions. Thermocycling at 5,000 cycles is similar to approximately six months in the oral environment. ${ }^{22}$ Thermocycling would induce stresses on the adhesive interface due to aging and thermal changes. ${ }^{39}$ The mechanism of bond degradation with the one-step self-etch adhesive could be attributed to hydrolysis and breakdown by enzymatic catalysis of partially exposed collagen under the hybrid layer. ${ }^{40}$ According to the results, there was decreased SBS in enamel and dentin with all the materials except the G-aenial Bond group, but this decrease was not statistically significant compared with the control group. However, there was a contradictory result regarding the effect of the thermocycling procedure on bond strength, although one meta-analysis study showed that thermocycling did not have a significant effect on bond strength. ${ }^{41}$

G-aenial Bond showed better resistance to the thermocycling procedure and two weeks' storage in artificial saliva compared with the other materials. The results showed significantly higher SBS in the enamel group after thermocycling. The mean SBS decreased with the dentin group but was not significantly different. The result in the present study is in agreement with that of two previous studies. Torkabadi and others evaluated the microtensile bond strength of G-aenial Bond after one year of water storage. The mean bond strength value decreased with time but was not significantly different. ${ }^{42}$ Another study, by Tekce and colleagues, revealed the same findings. ${ }^{43}$ The resistance of $\mathrm{G}$-aenial Bond to deterioration could be attributed to the absence of HEMA, considering the deteriorating effect of HEMA over time. Further studies are needed to support these hypotheses.

For the Bond-1 SF and G-aenial groups, most of the failure modes were classified as adhesive failures, confirming the poor performance and low bond strength of these adhesive systems when bonded to enamel and dentin. A high prevalence of the mixed-failure type was observed with OptiBond All-In-One and Single Bond Universal, even after thermocycling, when used with the enamel and dentin groups.

In general, bond strength to dentin was significantly higher than that to enamel with one-step self-etch adhesives. Suggestions have been proposed to improve bond strength, reduce water absorption, and decrease collagen degradation. These measures include selective enamel etching, the application of more than one coat, active application by scrubbing vigorously onto the surface, and the application of an extra hydrophobic resin coating to improve the in vitro and clinical performance of one-step selfetch adhesives. ${ }^{44}$

Within the limitations of this study, the results showed that lack of solvent in self-etch adhesive systems might lead to low adhesive performance and decreased bond strength. The results indicate that solvents are beneficial for the integrity of self-etch adhesives. It should be remembered, however, that the type of solvent, its properties, and the other chemical components as one mixture might affect the mechanical properties of adhesive.

\section{Conclusion}

Given the limitations of this experimental study, the following conclusions were drawn:

- Solvents and co-solvents play a significant role in the bond strength of one-step self-etch adhesives to enamel and dentin. Thus, comparison of solvent-containing with solventfree adhesives revealed that the composition of the self-etch bonding agent does affect its bonding mechanism.

- One-step self-etch adhesives containing ethanol as the solvent or co-solvent showed higher SBS when compared with the other self-etching bonding agents tested in the current research. 
- Bond strength values of one-step self-etch adhesives containing various solvents to dentin are significantly higher than those to enamel.

- Thermocycling procedures decreased the bond strength of one-step self-etch adhesives in the dentin group.

\section{Clinical Significance}

The types of solvents of one-step self-etch adhesives had an effect on SBS, and the absence of solvent in those adhesives would adversely influence their performance.

\section{References}

1. Van Meerbeek B, Perdigao J, Lambrechts $P$, et al. The clinical performance of adhesives. J Dent 1998 Jan;26(1):1-20. DOI: 10.1016/ S0300-5712(96)00070-X.

2. Buonocore MG. A simple method of increasing the adhesion of acrylic filling materials to enamel surfaces. J Dent Res 1955 Dec;34(6): 849-853. DOI: 10.1177/00220345550340060801.

3. Nakabayashi N, Kojima K, Masuhara E. The promotion of adhesion by the infiltration of monomers into tooth substrates. J Biomed Mater Res 1982 May;16(3):265-273. DOI: 10.1002/jbm.820160307.

4. Pashley DH, Tay FR, Breschi L, et al. State of the art etch-andrinse adhesives. Dent Mater 2011 Jan;27(1):1-16. DOI: 10.1016/ j.dental.2010.10.016.

5. Pashley DH, Ciucchi B, Sano H, et al. Permeability of dentin to adhesive agents. Quintessence Int 1993 Sep;24(9):618-631.

6. Tay FR, Gwinnett AJ, Pang KM, et al. Variability in microleakage observed in a total-etch wet-bonding technique under different handling conditions. J Dent Res 1995 May;74(5):1168-1178. DOI: 10.1177/00220345950740050501.

7. Frankenberger R, Kramer N, Petschelt A. Technique sensitivity of dentin bonding: effect of application mistakes on bond strength and marginal adaptation. Oper Dent 2000 Jul-Aug;25(4):324-330.

8. Van Meerbeek B, Yoshihara K, Yoshida Y, et al. State of the art of self-etch adhesives. Dent Mater 2011 Jan;27(1):17-28. DOI: 10.1016/ j.dental.2010.10.023.

9. Van Meerbeek B, Peumans M, Poitevin A, et al. Relationship between bond-strength tests and clinical outcomes. Dent Mater 2010 Feb;26(2):e100-e121. DOI: 10.1016/j.dental.2009.11.148.

10. Van Landuyt KL, Mine A, De Munck J, et al. Are one-step adhesives easier to use and better performing? Multifactorial assessment of contemporary one-step self-etching adhesives. J Adhes Dent 2009 Jun;11(3):175-190.

11. Sano H, Yoshikawa T, Pereira PN, et al. Long-term durability of dentin bonds made with a self-etching primer, in vivo. J Dent Res 1999 Apr;78(4):906-911. DOI: 10.1177/00220345990780041101.

12. Tay FR, Gwinnett AJ, Wei SH. The overwet phenomenon: an optical, micromorphological study of surface moisture in the acidconditioned, resin-dentin interface. Am J Dent 1996 Feb;9(1):43-48.

13. Giannini M, Makishi $P$, Ayres AP, et al. Self-etch adhesive systems: a literature review. Braz Dent J 2015 Jan-Feb;26(1):3-10. DOI: 10.1590/0103-6440201302442.

14. Kanca 3rd J. Resin bonding to wet substrate. 1. Bonding to dentin. Quintessence Int 1992 Jan;23(1):39-41.

15. Poggio C, Beltrami R, Scribante A, et al. Shear bond strength of onestep self-etch adhesives: pH influence. Dent Res J (Isfahan) 2015 May-Jun;12(3):209-214.

16. ra dos Led $\mathrm{S}, \mathrm{mm}$ de $\mathrm{A} P, \mathrm{Abl}$ do $\mathrm{N}$, et al. Bond strength to dentin of total-etch and self-etch adhesive systems. RGO - Revista Gaúcha de Odontologia 2014 Mar;62(4):365-370. DOI: 10.1590/19818637201400040000022648.

17. Sharafeddin F, Choobineh MM. Assessment of the Shear Bond Strength between Nanofilled Composite Bonded to Glass-ionomer Cement Using Self-etch Adhesive with Different $\mathrm{pHs}$ and Total-Etch Adhesive. J Dent (Shiraz) 2016 Mar;17(1):1-6.
18. Malik S, Bal CS, Singh R. Tensile bond strength of total etch and self-etch adhesives on moist and dry dentin in vivo study. Indian J Comprehensive Dent Care 2014 Jul-Dec;4(2):422-427.

19. Subhra Dey AS, Kundapur SS, Das M, et al. Evaluation of the Effect of Different Contaminants on the Shear Bond Strength of a Two-step Self-etch Adhesive System, One-step, Self-etch Adhesive System and a Total-etch Adhesive System. J Int Oral Health 2016 Jan;8(3): 378-384.

20. Chaudhary SBR, Tayal A. Influence of different types of co-solvents on the bonding abilities of one step self-etching adhesives: An Ex vivo Study. Indian J Dent Sci 2016 Jan;8(4):221-225. DOI: 10.4103/09764003.196818.

21. Koliniotou-Koumpia E, Kouros P, Koumpia E, et al. Shear bond strength of a "solvent-free" adhesive vs contemporary adhesive systems. Braz J Oral Sci 2014 Mar;13(1):64-69. DOI: 10.1590/1677-3225v13n1a13.

22. Gale MS, Darvell BW. Thermal cycling procedures for laboratory testing of dental restorations. J Dent 1999 Feb;27(2):89-99. DOI: 10.1016/S0300-5712(98)00037-2.

23. Gurgan S, Alpaslan T, Kiremitci A, et al. Effect of different adhesive systems and laser treatment on the shear bond strength of bleached enamel. J Dent 2009 Jul;37(7):527-534. DOI: 10.1016/ j.jdent.2009.03.012.

24. Gregoire G, Dabsie F, Dieng-Sarr F, et al. Solvent composition of one-step self-etch adhesives and dentine wettability. J Dent 2011 Jan;39(1):30-39. DOI: 10.1016/j.jdent.2010.09.008.

25. Klein-Junior CA, Zander-Grande C, Amaral R, et al. Evaporating solvents with a warm air-stream: effects on adhesive layer properties and resin-dentin bond strengths. J Dent 2008 Aug;36(8):618-625. DOI: 10.1016/j.jdent.2008.04.014.

26. Shirban F, Khoroushi M, Shirban M. A new solvent-free one-step selfetch adhesive: bond strength to tooth structures. J Contemp Dent Pract 2013 Mar 1;14(2):269-274. DOI: 10.5005/jp-journals-10024-1312.

27. El Sayed HY, Abdalla Al, Shalby ME, et al. Effect of thermocycling on the micro-shear bond strength of solvent free and solvent containing self-etch adhesives to dentin. Tanta Dent J 2015 Mar;12(1):28-34. DOI: 10.1016/j.tdj.2014.09.001.

28. Van Landuyt KL, Snauwaert J, De Munck J, et al. Systematic review of the chemical composition of contemporary dental adhesives. Biomaterials 2007 Sep;28(26):3757-3785. DOI: 10.1016/ j.biomaterials.2007.04.044.

29. Van Landuyt KL, De Munck J, Snauwaert J, et al. Monomer-solvent phase separation in one-step self-etch adhesives. J Dent Res 2005 Feb;84(2):183-188. DOI: 10.1177/154405910508400214.

30. Van Landuyt KL, Snauwaert J, Peumans M, et al. The role of HEMA in one-step self-etch adhesives. Dent Mater 2008 Oct;24(10):1412-1419. DOI: 10.1016/j.dental.2008.02.018.

31. Yoshida Y, Nagakane K, Fukuda R, et al. Comparative study on adhesive performance of functional monomers. J Dent Res 2004 Jun;83(6):454-458. DOI: 10.1177/154405910408300604.

32. Jayasheel A, Niranjan N, Pamidi H, et al. Comparative Evaluation of shear Bond Strength. J Clin Exp Dent 2017 Jul;9(7):892-896.

33. Guo $X$, Spencer $P$, Wang $Y$, et al. Effects of a solubility enhancer on penetration of hydrophobic component in model adhesives into wet demineralized dentin. Dent Mater 2007 Dec;23(12):1473-1481. DOI: 10.1016/j.dental.2006.12.003.

34. Howannaphakorn T, Duangmanee $Y$, Siwapatt N, et al. Effects of Acetone Evaporation Duration of Dentin Bonding Agent on Microleakage. Naresuan University Journal Science and Technolog 2013 Aug;2:23-26.

35. Abate PF, Rodriguez VI, Macchi RL. Evaporation of solvent in onebottle adhesives. J Dent 2000 Aug;28(6):437-440. DOI: 10.1016/ S0300-5712(00)00018-X.

36. Wang $Y$, Spencer $P$, Yao $X$, et al. Effect of solvent content on resin hybridization in wet dentin bonding. J Biomed Mater Res A 2007 Sep 15;82(4):975-983. DOI: 10.1002/jbm.a.31232.

37. Yoshida Y, Yoshihara K, Nagaoka N, et al. Self-assembled Nanolayering at the Adhesive interface. J Dent Res 2012 Apr;91(4):376-381. DOI: $10.1177 / 0022034512437375$. 
38. Munoz MA, Luque I, Hass V, et al. Immediate bonding properties of universal adhesives to dentine. J Dent 2013 May;41(5):404-411. DOI: 10.1016/j.jdent.2013.03.001.

39. Helvatjoglu-Antoniades $\mathrm{M}$, Koliniotou-Kubia E, Dionyssopoulos $\mathrm{P}$. The effect of thermal cycling on the bovine dentine shear bond strength of current adhesive systems. J Oral Rehabil 2004 Sep;31(9):911-917. DOI: 10.1111/j.1365-2842.2004.01318.x.

40. Van Landuyt KL, De Munck J, Mine A, et al. Filler debonding \& subhybrid-layer failures in self-etch adhesives. J Dent Res 2010 Oct;89(10):1045-1050. DOI: 10.1177/0022034510375285.

41. Leloup G, $D^{\prime}$ Hoore W, Bouter D, et al. Meta-analytical review of factors involved in dentin adherence. J Dent Res 2001 Jul;80(7):1605-1614. DOI: 10.1177/00220345010800070301.
42. Torneck CD, Titley KC, Smith DC, et al. The influence of time of hydrogen peroxide exposure on the adhesion of composite resin to bleached bovine enamel. J Endod 1990 Mar;16(3):123-128. DOI: 10.1016/S0099-2399(06)81588-8.

43. Tekce N, Demirci M, Tuncer S, et al. Microtensile bond strength and sealing efficiency of all-in-one self-etching adhesives. Biotechnol Biotechnol Equip 2015 Feb;29(3):570-578. DOI: 10.1080/13102818.2015.1008875.

44. Sezinando A. Looking for the ideal adhesive - A review. Revista Portuguesa de Estomatologia Medicina Dentária e Cirurgia Maxilofacial 2014 Oct-Dec;55(4):194-206. DOI: 10.1016/ j.rpemd.2014.07.004. 